\title{
Üniversitelerde Kariyer Planlama Faaliyetleri Ekseninde Kariyer Merkezlerine Yönelik Bir Araştırma
}

\author{
Ezgi Cevher*
}

Süleyman Demirel Üniversitesi, Isparta MYO, Isparta.

\begin{abstract}
Öz
Üniversitelerde öğrencilerin çoğu artık eğitimleri ve kariyerleri için zamanların planlama yapma ile geçirirler. Her bir öğrenci için kariyer planlama süreci kendi deneyimleri, ilgileri, yetenekleri ve değerlerine göre farklllık gösterir. Öğrencilerin eğitimlerinin ilk veya son döneminde kariyer hedeflerine yönelik farkındalıklarl, geleceklerini yönlendirmede önemli bir unsurdur. Bu amaçla çalışmada Türkiye'deki kamu ve vakıf üniversitelerine yönelik "kariyer planlama faaliyetleri ve kariyer merkezleri" araştırılmıştır. Çalışmada, üniversitelerin kariyer merkezlerinin faaliyetleri, içerik çözümlemesine göre incelenmiştir. Amaç, üniversitelerin kariyer planlama faaliyetleri ekseninde kariyer merkezlerini incelemek, kariyer faaliyetlerini tespit etmek ve kamu üniversiteleri ile vakı üniversitelerinin kariyer çalışmalarını karşılaştırmaktır. Çalışma, kariyer merkezlerinin önemine vurgu yapılarak görüş ve öneriler ile desteklenmiştir.
\end{abstract}

Anahtar Kelimeler: Kariyer, Kariyer Planlama, Kariyer Merkezleri, Üniversiteler

\section{A Study on Career Planning Centers at Universities in Terms of Career Planning Activities}

\begin{abstract}
Most of university students spend their time to make planning for their educations and careers. The career planning process for each student varies according to their experiences, interests, skills and values. In their first and last phase of education awareness of students on their career objectives is an important element in directing the future. For this purpose, in this study career planning activities and career centers" of state and foundation universities in Turkey have been searched. In this study, activities of career centers at universities have been determined in the context of content analysis. The purpose is to examine the career centers in terms of career planning activities at universities, to determine the career activities and to compare the career studies of state universities with foundation universities. The study has been supported by the opinions and recommendations by emphasizing the importance of career centers.
\end{abstract}

Keywords: Career, Career Planning, Career Centers, Universities

\section{GİRIŞ}

Türkiye' de yükseköğretim sistemi içerisinde kamu üniversitelerinin yanında vakıf üniversitelerinin de hıla kurulması, bu sisteme yeni bir rekabet ortamı kazandırmıştır. $\mathrm{Bu}$ rekabet, kamu üniversiteleriyle vakıf üniversiteleri karşılaştırıldığında, hem üniversiteye girecek öğrencilere seçenek sunma yönünde hem de kaliteyi artırıcı bir ortam oluşturma yönünde olmuştur. Bu nedenle gün geçtikçe ülkemizde yükseköğretim alanında üniversiteler gelişmekte, yeni üniversitelerinin kurulması desteklenmektedir. Yükseköğretimde artan bu rekabet ile birlikte, 
öğrencilerin iş dünyasının ihtiyaç ve beklentilerine uygun yetiştirilmesi gerekliliği gündeme gelmiştir. Öğrencilerin mezuniyet sonrası istihdamının önemli hale gelmesi, bu kitlenin yeni beklentilerden ve ihtiyaçlardan haberdar edilmesine neden olmuştur. Bu süreçte öğrencilerin kariyerleri ile ilgili yönlendirilmesi ve kariyer planlamaları da gündeme gelen diğer konular arasındadır.

Kariyer planlamada; öğrenci, öğretim elemanı ve üniversite paydaşlarının etkin şekilde örgütlenmesi bu çerçevede öğrencilere kariyer danışmanlığı hizmetlerinin verilmesi söz konusudur. Özellikle öğrencilerin iş dünyası ile kuracakları ilişkilerde bu merkezlerin birer köprü olması, merkezler aracılığıyla işbirliği ortamlarının hazırlanması bu hizmetlerin başında gelmektedir. Bu amaçla çalışmada, günümüzde iş yaşamına kalifiye eleman yetiştiren üniversitelerin kariyer merkezleri incelenmiştir. Üniversitelerin kariyer merkezlerinin faaliyetlerinin kariyer danışmanlı̆̆1 ekseninde karşılaştırılması amaçlanmış, kariyer planlaması açısından faaliyetlerin içeriği esas alınarak görüş ve öneriler sunulmuştur.

\section{KARIYYR KAVRAMI VE KARIYYER PLANLAMA}

Kariyer kelime olarak "bireyin çalışma yaşamında izlediği yol, çalıştığı alan, başlangıç yaptığı, çalışma yaşamının sonuna dek sürdürdüğü iş ya da pozisyon" şeklinde tanımlanmakta ve kariyer sözcüğ̈̈ kimi zaman meslek sözcüğü yerine kullanılmaktadır (Demirbilek, 1994). Kariyer "yol", "koşu yeri", "geçit" gibi sözlük anlamları içeren İngilizce "career" kelimesinin Türkçe karşılığ 1 olarak karşımıza çıkmıştır (İbicioğlu, 2011). Kariyer ile ilgili başka tanımlar incelendiğinde kariyer, genel olarak "çalışma yaşamında ilerleme sağlayıcı bir başarı elde edebilmek amacıyla bireyin izlediği yol, süreç veya çalıştığı alan" şeklinde ifade edilmiştir. Kariyer sözcüğü kimi zaman bireysel bir ilerleme kimi zaman da mesleki gelişme anlamlarında kullanılmaktadır (Noe, 2009). Genel olarak bireyin tüm yaşamını içeren kariyer kavramı (Can ve Güney, 2007) "bireyin herhangi bir iş alanında adım adım ilerlemesi ve deneyim kazanması" anlamına da gelmekte (Güney, 2000) bireyin yaşamı boyunca geliştirdiği tutumları, bilgi düzeyi ve yeterlilikleri gibi zaman içinde iş faaliyetleri ve pozisyonları dizisi olarak da tanımlanmaktadır (Gürüz, 2009:184; Yalım:2005:160-165).

Kariyer planlamasının iki boyutuna bağlı olarak gelişen bireysel kariyer planlama ise kişinin sahip olduğu bilgi, yetenek, beceri ve güdülerinin geliştirilmesiyle, çalışmakta olduğu örgüt içerisindeki ilerleyişinin ya da yükselmesinin planlamasıdır. Bu doğrultuda kariyer planlaması, geleceği tahmin edebilen, kendisini neyin beklediğini bilen, amaçlarını belirleyen, motive olabilen bireyler oluşturma gibi bir misyona da sahiptir (Barutçugil, 2004). Bireylerin geniş istihdam olanaklarını sağlayabilmeleri için öncelikle bireysel sorumluluklar almaları bunun için de kendi bireysel planlarını oluşturmaları önemli hale gelmektedir (Anafarta, 2001). Buna bağlı olarak bireysel sorumluluk alanının bir parçası olan bireysel kariyer planlamanın aşamaları ise şunlardır (Anafarta, 2002):

- Bireyin yeteneklerini değerlendirmesi, kendini tanıması

- İlgi alanlarını değerlendirmesi, 
- Kariyer fırsatlarını incelemesi,

- Kariyer amaçlarını ortaya koyması,

- Amaçlarına uygun faaliyetleri planlamasıdır.

Bir başka açıdan bireysel kariyer planlama süreci (Gürüz, 2009: 190) kendini tanıma, mesleği ve iş dünyasını tanıma, kendine uygun iş bulma, kariyerde ilerleme şeklinde de özetlenmektedir. Bu çalışmada, bireysel kariyer planlamanın sürecine yönelik bu beş aşama ekseninde kariyer merkezlerinin çalışmaları tespit edilmeye çalışılmıştır.

\section{1. Üniversiteler ve Kariyer Geliştirme Merkezleri}

Son dönemlerde özel olarak kariyer konusuna eğilen kimi araştırmacıların odaklandığı temel nokta üniversite öğrencilerinin kariyer planlarını etkileyen faktörlerdir (Yılmaz vd., 2012; Sağdıç ve Demirkaya, 2009; Fischer vd., 2003). Kariyer planlamanın temel belirleyicileri arasında cinsiyet ve kişisel özellikler, aile ve arkadaş çevresi yer alırken (Adıgüzel, 2008) bunlar dişında yetenek testleri, motivasyon, iş deneyimi, bireysel karakteristik özellikler, coğrafi konum, eğitim de kariyer planlama sürecini etkilemektedir (Rood, 1965). Günümüzde eğitim-öğretim hizmetlerinin gelişmesi sonucu yükseköğretimde meydana gelen rekabetle birlikte, iş dünyasına nitelikli eleman sağlama konusunda da çalışmalar yaygınlaşmıştır. Bireysel kariyer planlamayı etkileyen unsurlardan olan eğitim faktörü yukarıda bahsedilen araştırmalarda da belirtildiği üzere üniversitelerde önemli hale gelmiştir. Eğitimin bir unsuru olan kariyer geliştirme ve danışmanlık hizmetleri de özellikle bu kurumlarda destek hizmetler çerçevesinde verilmeye başlanmıştır (Cevher, 2013: 170).

Bu doğrultuda 12 Haziran 2013 tarihinde Yükseköğretim Kurulu ev sahipliğinde kariyer merkezleri toplantısı gerçekleştirilmiştir. Üniversite öğrencilerinin iş yaşamına hazırlanması ve staj uygulamalarının etkin bir biçimde yürütülmesi için üniversitelerde kurulan kariyer merkezlerinin yaptığ örnek uygulamalar bu toplantıda paylaşılmıştır (http://www.yok.gov.tr/web/ogrenci/kariyer-merkezleritoplantisi, Erişim: 16.06.2015). Özellikle öğrencilerin istihdam imkanlarını artırmak için henüz mezun olmadan staj ve bunun gibi uygulamalarla istihdama imkan veren kariyer merkezlerinin önemi vurgulanmış, dünyanın gelişmiş üniversitelerinde kariyer merkezlerinin bu konulara bir çözüm olarak ortaya çıtı̆̆ı, Türkiye' de de kariyer merkezlerinin ortaya çıkmaya başladığı belirtilmiştir.

Bugün, pek çok üniversitenin fakültelerinde piyasaya eleman yetiştirmek ve yönlendirmek amacıyla kariyer merkezleri kurulmuştur. Öğrencilerin kariyer planlamasına destek veren bu merkezler, öğrencilere bilinçli şekilde kariyer planlaması yapmalarına teşvik etmekte ve yön göstermektedirler. Bu merkezler aracılığıyla piyasada staj olanağı sağlanmakta, iş dünyasından isimler kariyer günleri etkinliklere davet edilmektedir (Sav, 2008: 81).

Kariyer yönetimi aracı olarak kullanılan kariyer merkezleri, bireylerin kendilerini değerlendirmelerine olanak veren, eğitim ve danışmanlık hizmeti veren örgüt içi kuruluşlardır. Bu merkezler, workshoplar oluşturur, kurslar düzenler, 
bireylere kendilerini analiz etme ve kariyer planları yapma olanağı tanır, uygun fırsatları bilmelerine yardımcı olurlar. Örgüt içi ve dışı eğitim programları düzenleyerek, iş açığına yönelik duyuruları yaparlar. Ayrıca kariyer bilgi sistemi fonksiyonuna da sahiptirler (Ünver, 2005: 42).

Türkiye'deki üniversitelerden birkaç örnek incelendiğinde kariyer merkezlerinin kuruluş süreçleri öncelikli olarak Sağlık Kültür Spor Daire Başkanlığına bağlı merkez olarak başlamış, Rektörlüğe bağlı Araştırma ve Uygulama Merkezi şeklinde devam etmiştir. Bugün kariyer merkezi olan üniversitelerden İstanbul Üniversitesinde Kariyer Danışmanlığı tezsiz yüksek lisans programı mevcuttur. Avrupa Üniversiteler Birliği'nin öğrenci odaklı yaklaşımı son dönemlerde Türkiye'deki üniversiteleri de kariyer merkezi kurmaya yönlendirmiştir. İstanbul Teknik Üniversitesi İş ve İnsan Kaynakları Merkezinin faaliyetleri ise 1998 yılında kariyer ofisi adı altında başlatılmıştır (http://www.yok.gov.tr/web/ogrenci/kariyermerkezleri-toplantisi, Erişim: 16.06.2015). Bu bilgilere bağlı olarak Türkiye' de ki üniversitelerde kariyer merkezlerinin yeni bir yapılanma süreci içerisinde olduğu söylenebilir. Bu çalışmada özellikle kariyer merkezleri araştırmasının yapılması da üniversitelere görüş ve tavsiyelerde bulunmak, merkezlerin açılması adına farkındalık yaratmak içindir.

\section{2. ÜNIVERSITELERDE KARIYYER PLANLAMA FAALIYYETLERİ VE KARIYYER MERKEZLERİ ARAŞTIRMASI}

\subsection{Araştırmanın Amacı ve Yöntemi}

$\mathrm{Bu}$ araştırmanın amacı, yükseköğretim alanında faaliyet gösteren kamu ve vakıf üniversitelerinin kariyer geliştirme merkezlerini araştırmak, kariyer planlama faaliyetleri ekseninde kariyer merkezleri faaliyetlerini kıyaslamaktır. Öğrencilerin kariyer planlama yapabilmeleri ve kariyerlerine yön verebilmeleri amaciyla kariyer geliştirme merkezlerinin faaliyetlerini esas alarak merkezlere yönelik farkındalık oluşturmada görüş ve öneriler sunmaktır.

Araştırmada analiz yöntemlerinden nitel analiz tekniği kullanılmıştır. Bütüncül bir yaklaşıma sahip olarak bilinen nitel analizi nicel analizden ayıran en önemli özellik algıların ortaya konması ve tümevarımcı bir özelliğe sahip olmasıdır (Külekçi, 2013:371). Veri toplama aracı olarak doküman analiziyle yapılan, mesajların gerçekçi ve bütüncül bir anlayışla ortaya konduğu ve bu amaca yönelik analizde belirli aşamaların izlendiği (Yılmaz, 2001:5). Bu araştırmada içerik analizi uygulanmıştır. Bunun için 109 kamu üniversitesinden 103 kamu üniversitesi, 71 vakıf üniversitesinden de 68 vakıf üniversitesi (yok.gov.tr. Erişim: 16.06.2015). olmak üzere toplamda 171 üniversite incelenmiştir. Bu şekilde araştırmanın örneklemini 171 üniversite oluşturmuştur.

Bilimsel bir yaklaşım olarak içerik analizinde; sözel, yazılı ve diğer materyallerin içerdiği mesajı, anlam veya dilbilgisi açısından nesnel ve sistematik olarak sınıflandırma, sayılara dönüştürme ve çıkarımda bulunma yoluyla sosyal gerçeği araştırma söz konusudur (Tavşancıl ve Aslan, 2001: 22). İçerik analizi; iletilerin, 
açık ve görünen içeriğinin, nesnel, ölçülebilir ve doğrulanabilir bir açıklamasını yapabilmek amacıyla kullanılmaktadır. Buna göre üniversitelerde yer alan kariyer merkezleri seçilmiş; bu kariyer merkezleri faaliyetleri ayrıntılı şekilde incelenmiştir. Bu noktada öncelikli olarak araştırmaya dahil edilen üniversitelerin;

- Kuruldukları iller,

- Kuruluş tarihlerine göre kaç yıllık üniversite oldukları,

- Kariyer merkezi sahibi olup olmadıkları,

- Kariyer merkezinin nasıl isimlendirildiği,

- Merkezde yürütülen faaliyetler,

- Kariyer planlama faaliyetlerinin var olup olmadığı,

- Verilen danışmanlık hizmetleri incelenmiş ve analiz edilmiştir.

Kariyer merkezlerine yönelik belirlenen bu kategoriler, her bir kategori altında yer alan alt kategorilerle desteklenmiş ve kodlanmıştır. Kodlama yapıldıktan sonra elde edilen veriler SPSS paket programında sayısallaştırılmıştır. Son bölümde bulguları destekleyecek şekilde vakıf ve kamu üniversiteleri kıyaslanmış, bulgular görüş ve önerilerle desteklenmiştir.

\subsection{Araştırmanın Bulguları}

Çalışmaya dahil edilen üniversitelere yönelik kariyer merkezleri araştırıldığında aşağıdaki bulgulara ulaşılmıştır.

Tablo 1. Araştırmaya Dahil Edilen Üniversite Sayıları ve Kurum Türleri

\begin{tabular}{|l|c|c|}
\hline KURUM TÜRÜ & FREKANS & YÜZDE \\
\hline Kamu Üniversitesi & 103 & $\% 60.2$ \\
\hline Vakıf Üniversitesi & 68 & $\% 39.8$ \\
\hline TOPLAM & $\mathbf{1 7 1}$ & $\mathbf{\%} \mathbf{1 0 0 , 0}$ \\
\hline
\end{tabular}

Araştırmada 103 kamu üniversitesi ve 68 vakıf üniversitesi incelenmiştir. 20132014 eğitim öğretim yılında faaliyet gösteren 109 kamu üniversitesinden 103 ü örneklem olarak ele alınmıştır. Asker polis teşkilatındaki yükseköğretim kurumları araştırmaya dahil edilmemiştir. Tablo 2 incelendiğinde araştırmaya dahil edilen kamu üniversitelerinden \% 7,8'inin İstanbul; \% 5,8'inin Ankara; \% 3,9'unun da İzmir merkezli olduğu görülmektedir. \% 1,9 oranında ise kamu üniversitelerinin Bursa, Konya ve Eskişehir merkezli olduğu elde edilen bulgular arasındadır. Kamu üniversitelerinin kurulduğu iller en yüksek oranı ise \% 76,7 ile diğer iller kategorisindedir. Vakıf üniversitelerinin kuruldukları iller ise sırasıyla \% 52,9 oranında İstanbul; \% 16,2 oranında Ankara; \% 5,9 oranında İzmir; \% 4,4 oranında Konya; \% 1,5 oranında Bursa şeklindedir. \% 19,1 oranında diğer iller kategorisinde de vakıf üniversiteleri yer almaktadır. 
Tablo 2. Araştırmada Yer Alan Üniversitelerin Kuruluş Yerleri

\begin{tabular}{|l|c|c|c|c|}
\hline \multirow{2}{*}{$\begin{array}{c}\text { ÜNIVERSITELER VE } \\
\text { ŞEHİRLER }\end{array}$} & \multicolumn{2}{|c|}{$\begin{array}{c}\text { KAMU } \\
\text { ÜNIVERSITELERI }\end{array}$} & \multicolumn{2}{c|}{} \\
\cline { 2 - 5 } & FREKANS & YÜZDE & FREKANS & YÜZDE \\
\hline İstanbul & 8 & $\% 7,8$ & 36 & $\% 52,9$ \\
\hline Ankara & 6 & $\% 5,8$ & 11 & $\% 16,2$ \\
\hline İzmir & 4 & $\% 3,9$ & 4 & $\% 5,9$ \\
\hline Bursa & 2 & $\% 1,9$ & 1 & $\% 1,5$ \\
\hline Konya & 2 & $\% 1,9$ & 3 & $\% 4,4$ \\
\hline Eskişehir & 2 & $\% 1,9$ & 0 & $\% 0$ \\
\hline Diğer İller & 79 & $\% 76,7$ & 13 & $\% 19,1$ \\
\hline TOPLAM & $\mathbf{1 0 3}$ & $\mathbf{\% 1 0 0 , 0}$ & $\mathbf{6 8}$ & $\mathbf{\%} \mathbf{1 0 0 , 0}$ \\
\hline
\end{tabular}

Araştırmada üniversitelerin kuruldukları şehirlere bakıldığında kamu üniversitelerinin daha çok İstanbul, Ankara, İzmir gibi büyük şehirlerin dışında; vakıf üniversitelerinin de İstanbul ve Ankara' da kurulduğu görülmektedir.

Tablo 3. Kuruldukları Yıllara Göre Üniversitelerin Tarihleri

\begin{tabular}{|c|c|c|c|c|}
\hline \multirow{2}{*}{$\begin{array}{l}\text { ÜNIVERSİTELER VE } \\
\text { KURULUŞ YILLARI }\end{array}$} & \multicolumn{2}{|c|}{$\begin{array}{c}\text { KAMU } \\
\text { ÜNIVERSİTELERİ }\end{array}$} & \multicolumn{2}{|c|}{$\begin{array}{c}\text { VAKIF } \\
\text { ÜNIVERSİTELERİ }\end{array}$} \\
\hline & FREKANS & YÜZDE & FREKANS & YÜZDE \\
\hline 1-10 Yıllık Üniversite & 50 & $\% 48,5$ & 44 & $\% 64,7$ \\
\hline 11-20 Yillık Üniversite & 2 & $\% 1,9$ & 20 & $\% 29,4$ \\
\hline 21-30 Yillık Üniversite & 21 & $\% 20,4$ & 3 & $\% 4,4$ \\
\hline 31-40 Y1llık Üniversite & 10 & $\% 9,7$ & 1 & $\% 1,5$ \\
\hline 41-50 Yıllık Üniversite & 10 & $\% 9,7$ & 0 & $\% 0$ \\
\hline 50 Yildan Fazla & 10 & $\% 9,7$ & 0 & $\% 0$ \\
\hline TOPLAM & 103 & $\% 100$ & 68 & $\% 100$ \\
\hline
\end{tabular}

Tablo 3 incelendiğinde kamu üniversitelerinin \% 48,5 oranında 1-10 yıllık üniversiteler olduğu; \% 20,4'ünün de 21-30 yıllık üniversite olduğu görülmektedir. Bu oranlar vakıf üniversitelerinde ise \% 64,7 ile geçmişi 1-10 yıllık ve \% 29,4 ile 11-20 yıllık olan üniversitelerden oluşmaktadır. Bu oranlar dikkate alındığında hem kamu hem de vakıf üniversitelerinin büyük çoğunluğunun yeni kurulan üniversiteler olduğu söylemek mümkündür.

Tablo 4. Kariyer Merkezi Olan ve Olmayan Üniversitelere Yönelik Bulgular

\begin{tabular}{|l|c|c|c|c|}
\hline \multicolumn{1}{|c|}{ KARIYYER } \\
MERKEZI OLAN \\
$\begin{array}{c}\text { VE OLMAYAN } \\
\text { ÜNIVERSITTELER }\end{array}$ & \multicolumn{2}{|c|}{ KAMU } & \multicolumn{2}{c|}{$\begin{array}{c}\text { VAKIF } \\
\text { ÜNIVERSIVERSITI }\end{array}$} \\
\cline { 2 - 5 } & FREKANS & YÜZDE & FREKANS & YÜZDE \\
\hline Merkezi olan & 45 & $\% 43,7$ & 33 & $\% 48,5$ \\
\hline Merkezi olmayan & 58 & $\% 56,3$ & 35 & $\% 51,5$ \\
\hline TOPLAM & $\mathbf{1 0 3}$ & $\mathbf{\%} \mathbf{1 0 0 , 0}$ & $\mathbf{6 8}$ & $\mathbf{\% 1 0 0 , 0}$ \\
\hline
\end{tabular}

Araştırmada incelenen 103 kamu üniversitesinin \% 43,7'sinde kariyer merkezi olduğu bulgusuna rastlanmıştır. Merkezi olmayan kamu üniversitesi oranı ise \% 
56,3'tür. Buna göre kamu üniversitelerinin neredeyse yarısının "kariyer planlama ve kariyer geliştirme" faaliyetlerini yerine getirdiği, böyle bir çaba içerisinde bulunduğu söylenebilir. Vakıf üniversitelerinin ise \% 48,5'inde kariyer merkezi yer almaktadır. Kamu üniversiteleri ve vakıf üniversiteleri karşılaştırıldığında, vakıf üniversitelerinin oran olarak daha fazla kariyer geliştirme çabalarına önem verdiği ve daha fazla oranda merkez açtıkları söylenebilir. Bu noktada kamu üniversitelerinin ve vakıf üniversitelerinin hedef kitlesini öğrencilerin oluşturduğu düşüncesinden yola çıkılarak üniversitelerin öğrenci sayılarına da değinmek önemli olabilir.

Türkiye'de 2013-2014 Eğitim öğretim yılında öğrenim gören öğrenci sayıları, kamu üniversitelerinde 5.089.291 iken; vakıf üniversitelerinde 350.999'dur (Nisan 2014 YÖK Verileri, Aktaran: Çetinsaya, 2014: 68). Öğretim türü ve yükseköğretimde kurum türlerine göre öğrenci sayıları ile dağılım oranları aşağıdaki tabloda yer almaktadır: $\mathrm{Bu}$ tabloya bakıldığında kariyer planlama ve uygulama merkezlerinin öğrenci odaklı olduğu düşünülürse her iki kurum türünde de bu merkezlerin açılmasının gündeme gelmesi söz konusu olabilir. Zira kamu üniversitelerinde pek çok kariyer merkezi resmi gazetede yayınlanmış yönetmelik ekseninde 2014 ve 2015 yıllarında yeni kurulmuştur.

Tablo 5. Türkiye'deki Kamu ve Vakıf Üniversitelerinin Öğrenci Sayıları

\begin{tabular}{|l|c|c|c|c|}
\hline \multirow{2}{*}{$\begin{array}{c}\text { ÜNIVERSITELER } \\
\text { VE PROGRAM } \\
\text { TÜRLERİ }\end{array}$} & \multicolumn{2}{|c|}{ KAMU } & \multicolumn{2}{c|}{ VAKIF } \\
\cline { 2 - 5 } & $\begin{array}{c}\text { TOPLAM } \\
\text { SAYI }\end{array}$ & $\begin{array}{c}\text { TOPLAM } \\
\text { YÜZDE }\end{array}$ & $\begin{array}{c}\text { TOPLAM } \\
\text { SAYI }\end{array}$ & $\begin{array}{c}\text { TOPLAM } \\
\text { YÜZDE }\end{array}$ \\
\hline Ön Lisans & 1683044 & $\% 30,9$ & 57418 & $\% 1,1$ \\
\hline Lisans & 3139516 & $\% 57,6$ & 231172 & $\% 4,2$ \\
\hline Lisans Üstü & 266731 & $\% 4,9$ & 62409 & $\% 1,1$ \\
\hline GENEL TOPLAM & $\mathbf{5 0 8 9 2 9 1}$ & $\mathbf{9 0 9 3 , 4}$ & $\mathbf{3 5 0 9 9 9}$ & $\mathbf{9 6 , 4}$ \\
\hline
\end{tabular}

Kaynak: Gökhan Çetinsaya, Büyüme Kalite Uluslararasılaşma Türkiye Yükseköğretimi İçin Bir Yol Haritası, Haziran 2014, s. 68

Tablo 6. Kariyer Merkezi Sayfası Olup Olmadığına İlişkin Bulgular

\begin{tabular}{|l|c|c|c|c|}
\hline $\begin{array}{c}\text { KARIYER MERKEZI } \\
\text { SAYFASI OLAN } \\
\text { ÜNIVERSITELER }\end{array}$ & \multicolumn{2}{|c|}{ KAMU ÜNIVERSITESI } & \multicolumn{2}{|c|}{ VAKIF ÜNIVERİTESİ } \\
\cline { 2 - 5 } & FREKANS & YÜZDE & FREKANS & YÜZDE \\
\hline Sayfası var & 26 & $\% 25,2$ & 29 & $\% 42,6$ \\
\hline Sayfası yok & 77 & $\% 74,8$ & 39 & $\% 57,4$ \\
\hline TOPLAM & $\mathbf{1 0 3}$ & $\mathbf{\% ~ 1 0 0 , 0}$ & $\mathbf{6 8}$ & $\mathbf{\%} \mathbf{1 0 0 , 0}$ \\
\hline
\end{tabular}

Tablo 6 incelendiğinde elde edilen bulgular, üniversitelerin kariyer geliştirme sayfalarının var olup olmadığını tespit etmeye yönelik olmuştur. Pek çok güncel kariyer duyurusunun, haberlerin internet ortamından kullanıcılara ulaştırıldığı düşünülürse sayfaların var olup olmadığı, var ise etkin kullanılıp kullanılmadığının tespiti bir kriter kabul edilmiş ve bu alan özellikle incelenmiştir. Elde edilen bulgularda kamu üniversitelerinin \% 25,2'sinde; vakıf üniversitelerinin de \% 42,6'sında kariyer merkezi web sayfasına rastlanmıştır. Araştırmanın güvenirliliği açısından her 
üniversitenin ana web sayfası, Sağlık Kültür ve Spor Daire Başkanlığı sayfaları, Öğrenci İşleri Daire Başkanlığı Sayfaları, Öğrenci Dekanlığı Birimi sayfaları, Araştırma ve Uygulama Merkezleri sayfaları kontrol edilmiş, kariyer merkezi sayfası adresi araştırılmıştır. Var olan sayfalar incelenmiş, var olmayanlar için kodlama yönergesine "yoktur" kaydı yapılmıştır. Bazı üniversitelerin kariyer merkezi kurulmasına ve yönetmeliği Resmi Gazete' de yayınlanmasına rağmen, aktif şekilde faaliyet gösteremedikleri, birim web sayfalarının dahi olmadığı tespit edilmiştir. Bazı üniversitelerin ise sadece mezun portalı adı altında "kariyer planlama" ara yüzüne rastlanmıştır. Mezun bilgi sistemi olan üniversitelerin de olduğu tespit edilmiştir. Ancak bunlar online ortamda daha çok mezunlara sunulan hizmetler olduğundan araştırmada dikkate alınmamıştır. Bunlar dışında pek çok üniversitenin ana sayfasında duyurular ve etkinlikler bölümünde "kariyer günleri" haberlerine rastlanmıştır. Merkezi olmayan ancak kariyer günleri etkinliğini düzenleyen üniversite sayısının da oldukça fazla olduğu gözlemlenmiştir.

Kariyer merkezi sayfası olan üniversitelerin çoğunun sayfasına giriş şifre ile sağlandığı görülmüştür. Özgeçmiş oluştururken örnekler sayfalardan paylaşılmış, oluşturma aşaması şifre ile girişle kısıtlanmıştır. Boğaziçi Üniversitesi'nin en büyük insan kaynakları veri tabanına sahip sitelerden biri olan kariyer.net ile işbirliği protokolü imzalamış olmasına da araştırmada rastlanmıştır. Bu üniversite kariyer merkezi sayfasında sadece öğrencilere değil işverenlere de şifre ile giriş hizmeti sağlamıştır.

Tablo 7.Kamu Üniversiteleri Kariyer Merkezi Sayfalarında Sunulan Hizmetlere İlişkin Bulgular

\begin{tabular}{|l|c|c|c|c|c|c|}
\hline \multirow{2}{*}{$\begin{array}{l}\text { ÜNIVERSITELER VE } \\
\text { KARIYYER MERKEZI }\end{array}$} & \multicolumn{5}{|c|}{ KAMU ÜNIVERSITELERI } \\
\cline { 2 - 6 } $\begin{array}{l}\text { SAYFALARINDA } \\
\text { SUNULANLAR }\end{array}$ & FREKANS & \multirow{2}{*}{ TOPLAM } & \multicolumn{2}{|c|}{ YÜZDE } & \multirow{2}{*}{ VAR } \\
\cline { 2 - 3 } & VAR & YOK & & YOK & \\
\hline İlgili Form/Belgeler & 14 & 89 & $\mathbf{1 0 3}$ & $\% 13,6$ & $\% 86,4$ & $\mathbf{\% 1 0 0 , 0}$ \\
\hline Faydalı Linkler & 15 & 88 & $\mathbf{1 0 3}$ & $\% 14,6$ & $\% 85,4$ & $\mathbf{\% 1 0 0 , 0}$ \\
\hline Haberler / Duyurular & 26 & 77 & $\mathbf{1 0 3}$ & $\% 25,2$ & $\% 74,8$ & $\mathbf{\% 1 0 0 , 0}$ \\
\hline Sosyal Ağ Sayfası & 15 & 88 & $\mathbf{1 0 3}$ & $\% 14,6$ & $\% 85,4$ & $\mathbf{\% 1 0 0 , 0}$ \\
\hline E-Bülten & 4 & 99 & $\mathbf{1 0 3}$ & $\% 3,9$ & $\% 96,1$ & $\mathbf{\% 1 0 0 , 0}$ \\
\hline Etkinlik Takvimi & 16 & 87 & $\mathbf{1 0 3}$ & $\% 15,5$ & $\% 84,5$ & $\mathbf{\% 1 0 0 , 0}$ \\
\hline
\end{tabular}

Tablo 8. Vakıf Üniversiteleri Kariyer Merkezi Sayfalarında Sunulan Hizmetlere İlişkin Bulgular

\begin{tabular}{|c|c|c|c|c|c|c|}
\hline \multirow{3}{*}{\begin{tabular}{|l|} 
ÜNIVERSİTELER VE \\
KARIYYER MERKEZI \\
SAYFALARINDA \\
SUNULANLAR \\
\end{tabular}} & \multicolumn{6}{|c|}{ VAKIF ÜNIVERSİTELERİ } \\
\hline & \multicolumn{2}{|c|}{ FREKANS } & \multirow{2}{*}{ TOPLAM } & \multicolumn{2}{|c|}{ YÜZDE } & \multirow{2}{*}{ TOPLAM } \\
\hline & VAR & YOK & & VAR & YOK & \\
\hline İlgili Form/Belgeler & 19 & 49 & 68 & $\% 27,9$ & $\% 72,1$ & $\% 100,0$ \\
\hline Faydalı Linkler & 17 & 51 & 68 & $\% 25,0$ & $\% 75,0$ & $\% 100,0$ \\
\hline Haberler / Duyurular & 20 & 48 & 68 & $\% 29,4$ & $\% 70,6$ & $\% 100,0$ \\
\hline Sosyal Ağ Sayfası & 15 & 53 & 68 & $\% 22,1$ & $\% 77,9$ & $\% 100,0$ \\
\hline E-Bülten & 3 & 65 & 68 & $\% 4,4$ & $\% 95,6$ & $\% 100,0$ \\
\hline Etkinlik Takvimi & 17 & 51 & 68 & $\% 25,0$ & $\% 75,0$ & $\% 100,0$ \\
\hline
\end{tabular}


Tablo 7 ve 8 incelendiğinde kamu üniversitelerinin \% 25,2'sinin kariyer merkezi web sayfasında; vakıf üniversitelerinin \% 29,4'ünün sayfasında haberler ve duyurulara yer verildiği tespit edilmiştir. Kamu üniversitelerin web sayfasında sırasıyla sunulan diğer hizmetler \% 15,5 oranında etkinlik takvimi; \% 14,6 oranında faydalı linkler bağlantısı olmuştur. Sosyal ağ sayfası olan kamu üniversitesi kariyer merkezi oranı ise $\%$ 14,6'dır. Merkezlerin sayfasında ayrıca \% 13,6 oranında ilgili form ve belgelere; \% 3,9 oranında e-bültene yer verilmiştir. Vakıf üniversitelerinin kariyer merkezi web sayfasının \% 27,9'unda ilgili form ve belgeler bölümü yer almaktadır. Hatta Erciyes Üniversitesi'nin kariyer merkezi sayfasında faaliyet raporlarına da yer verdiği görülmüştür. \% 25'inin web sayfasında ise faydalı linkler ve etkinlik takvimi bölümlerine yer verilmiştir. Sosyal ağ sayfası olan vakıf üniversitesi kariyer merkezi oranı ise \% 22,1'dir. Bu oran kamu üniversiteleri kariyer merkezleri ile kıyaslandığında daha fazladır. Vakıf üniversitelerinin kariyer merkezleri faaliyetlerini sosyal medya ve sosyal paylaşım sitelerinden daha aktif şekilde yönettikleri söylenebilir. Facebook, Twitter, Linkedin, Google plus bu bağlantılardan bazılarıdır. Bazı üniversiteler kariyer merkezi sayfalarında, facebook gibi sosyal paylaşım sitesinde yer alan kariyer topluluklarının linkine de yer vermiştir. Sayfada sunulan hizmetlerin dişında merkez sayfasında sayfa içeriğinde kariyere yönelik görsel resimlere de rastlanmıştır. "Hedefe yönelmiş ok, merdivenlerden çıkan insanlar, toplantı yapan çalışanlar vb." gibi resimlere yer verilmiştir. Ortadoğu Teknik Üniversitesi kariyer web sayfasında "sizin öykünüz" isimli başlığı ile mezunlarının iş dünyasındaki pozisyon ve konumlarını paylaşmıştır.

Tablo 9. Kariyer Geliştirme Merkezi Birim İsimlerine Yönelik Bulgular

\begin{tabular}{|c|c|c|c|c|}
\hline \multirow{2}{*}{$\begin{array}{l}\text { ÜNIVERSITTELER VE KARIYYER } \\
\text { MERKEZLERİ İSIMMLERI }\end{array}$} & \multicolumn{2}{|c|}{$\begin{array}{c}\text { KAMU } \\
\text { ÜNIVERSİTELERİ }\end{array}$} & \multicolumn{2}{|c|}{$\begin{array}{c}\text { VAKIF } \\
\text { ÜNIVERSİTELERİ }\end{array}$} \\
\hline & FREKANS & YÜZDE & FREKANS & YÜZDE \\
\hline Kariyer Merkezi & 19 & $\% 18,4$ & 25 & $\% 36,7$ \\
\hline Kariyer Araştırma ve Geliştirme Merkezi & 19 & $\% 18,4$ & 1 & $\% 1,5$ \\
\hline Birim/Koordinatörlük & 7 & $\% 6,8$ & 7 & $\% 10,3$ \\
\hline Merkezi Olmayan & 58 & $\% 56,3$ & 35 & $\% 51,5$ \\
\hline TOPLAM & 100 & $\% 100$ & 68 & $\% 100$ \\
\hline
\end{tabular}

Kariyer Geliştirme Merkezi birim isimlerine yönelik bulgular incelendiğinde; kamu üniversitelerinin \% 18,4'ü; vakıf üniversitelerinin de \% 36,7'si “Kariyer Merkezi” adı altında bu birimleri kurmuşlardır. Vakıf üniversitelerinin kariyer merkezlerinin \% 10,3'ü; kamu üniversitelerinin ise \% 6,8'i “birim veya koordinatörlük" adı altında kurulmuşlardır. Kamu üniversitelerinde "Araştırma ve Uygulama Merkezi" olarak açılan kariyer merkezi oranı ise \% 18,4'tür. Araştırmada kamu üniversitelerinin kariyer merkezlerinin bazılarının Resmi Gazete' de yayınlanan yönetmelik çerçevesinde "Kariyer Geliştirme Araştırma ve Uygulama Merkezi"; bir kısmının Sağlık Kültür Spor Daire Başkanlığı altında "Kariyer Merkezi" şeklinde kurulduğu, bazılarının ise kariyer planlama adı altında "Koordinatörlük" olarak faaliyet gösterdiği tespit edilmiştir. Vakıf üniversiteleri araştırmasında bu üniversitelerin kariyer merkezlerinde çalışanların konumunun da farklı şekillerde isimlendirildiği görülmüştür. Kariyer 
Merkezi direktörü, işveren ilişkileri yöneticisi, kariyer danışmanı bu pozisyonlardan bazılarıdır.

Tablo 10. Kamu Üniversitelerinin Kariyer Planlama Hizmetlerine Yönelik Bulgular

\begin{tabular}{|c|c|c|c|c|c|c|}
\hline \multirow{3}{*}{$\begin{array}{l}\text { ÜNIVERSİTELER VE } \\
\text { KARIYYER PLANLAMA } \\
\text { HİZMETLERİ }\end{array}$} & \multicolumn{6}{|c|}{ KAMU ÜNIVERSİTELERİ } \\
\hline & \multicolumn{2}{|c|}{ FREKANS } & \multirow{2}{*}{ TOPLAM } & \multicolumn{2}{|c|}{ YÜZDE } & \multirow{2}{*}{ TOPLAM } \\
\hline & VAR & YOK & & VAR & YOK & \\
\hline Kendini Tanıma Faaliyetleri & 40 & 63 & 103 & $\% 38,8$ & $\% 61,2$ & $\% 100,0$ \\
\hline Mesleğini Tanıma & 26 & 77 & 103 & $\% 25,2$ & $\% 74,8$ & $\% 100,0$ \\
\hline İş Dünyasını Tanıma & 40 & 63 & 103 & $\% 38,8$ & $\% 61,2$ & $\% 100,0$ \\
\hline Kendine Uygun İş Bulma & 40 & 63 & 103 & $\% 38,8$ & $\% 61,2$ & $\% 100,0$ \\
\hline Kariyerde İlerleme & 13 & 90 & 103 & $\% 12,6$ & $\% 87,4$ & $\% 100,0$ \\
\hline
\end{tabular}

Tablo 11. Vakıf Üniversitelerinin Kariyer Planlama Hizmetlerine Yönelik Bulgular

\begin{tabular}{|c|c|c|c|c|c|c|}
\hline \multirow{3}{*}{$\begin{array}{l}\text { ÜNIVERSİTELER VE } \\
\text { KARIYYER PLANLAMA } \\
\text { HİZMETLERİ }\end{array}$} & \multicolumn{6}{|c|}{ VAKIF ÜNIVERSİTELERİ } \\
\hline & \multicolumn{2}{|c|}{ FREKANS } & \multirow{2}{*}{ TOPLAM } & \multicolumn{2}{|c|}{ YÜZDE } & \multirow{2}{*}{ TOPLAM } \\
\hline & VAR & YOK & & VAR & YOK & \\
\hline Kendini Tanıma Faaliyetleri & 33 & 35 & 68 & $\% 48,5$ & $\% 51,5$ & $\% 100,0$ \\
\hline Mesleğini Tanıma & 15 & 53 & 68 & $\% 22,1$ & $\% 77,9$ & $\% 100,0$ \\
\hline İş Dünyasını Tanıma & 33 & 35 & 68 & $\% 48,5$ & $\% 51,5$ & $\% 100,0$ \\
\hline Kendine Uygun İş Bulma & 33 & 35 & 68 & $\% 48,5$ & $\% 51,5$ & $\% 100,0$ \\
\hline Kariyerde İlerleme & 20 & 48 & 68 & $\% 29,4$ & $\% 70,6$ & $\% 100,0$ \\
\hline
\end{tabular}

Üniversitelerin kariyer merkezlerinde kariyer planlama faaliyetlerine yönelik faaliyetleri incelendiğinde kamu üniversitelerinde \% 38,8 oranında; vakıf üniversitelerinde ise \% 48,5 oranında "kendini tanıma, mesleğini tanıma, iş dünyasını tanıma, kendine uygun iş bulma, kariyerde ilerleme" faaliyetlerinin yürütüldüğü, bu alanda öğrencilerin yönlendirildiği ve bilgi verildiği tespit edilmiştir. Aktif şekilde faaliyetlerine rastlanmayan kamu üniversitelerinin ise Resmi Gazete' de yayınlanan yönetmelikleri ayrıntılı şekilde incelenmiş, kariyer planlama faaliyetlerine yönelik hizmetleri kodlama yönergesine işaretlenmiştir. Merkezlerde özellikle kendini tanıma faaliyetleri kapsamında ölçme ve değerlendirmeler yapıldığı, kişilik testlerinin uygulandığı; iş dünyasını tanımaya yönelik etkinliklerin yapıldığı, iş adamlarının konuşmacı olarak davet edildiği, konferansların düzenlendiği; iş ilanlarına yer verildiği görülmüştür.

Kariyer planlama ve geliştirme faaliyetlerini yürüten bazı üniversitelerin bu faaliyetlerinde oldukça aktif olduğu detaylı incelenen web sayfalarında gözlemlenmiştir. Özellikle bazı üniversitelerin faaliyetlerini insan kaynakları platformu ile yürüttükleri, doğrudan iş ilanlarına ve başvuruya öğrencilerini yönlendirdikleri tespit edilmiştir. Ya da kariyer merkezi sayfasında doğrudan iş ilanlarını paylaşan üniversitelerin olduğu da tespit edilmiştir. Üniversite aşamasındaki öğrencilerin bilgilendirilmesi adına da faaliyet yürüten üniversitelere rastlanmıştır. 
Tablo 12. Kamu Üniversitelerinin Danışmanlık Hizmetlerine Yönelik Bulgular

\begin{tabular}{|c|c|c|c|c|c|c|}
\hline \multirow{3}{*}{$\begin{array}{l}\text { ÜNIVERSITELER VE } \\
\text { DANIŞMANLIK } \\
\text { HİZMETLERİ }\end{array}$} & \multicolumn{6}{|c|}{ KAMU ÜNIVERSİTELERİ } \\
\hline & \multicolumn{2}{|c|}{ FREKANS } & \multirow{2}{*}{ TOPLAM } & \multicolumn{2}{|c|}{ YÜZDE } & \multirow{2}{*}{ TOPLAM } \\
\hline & VAR & YOK & & VAR & YOK & \\
\hline Lisansüstü Program & 10 & 93 & 103 & $\% 9,7$ & $\% 90,3$ & $\% 100,0$ \\
\hline Ölçme ve Değerlendirme & 9 & 94 & 103 & $\% 8,7$ & $\% 91,3$ & $\% 100,0$ \\
\hline Eğitim Programları & 40 & 63 & 103 & $\% 38,8$ & $\% 61,2$ & $\% 100,0$ \\
\hline Kariyer Bilgi Sistemi & 21 & 92 & 103 & $\% 20,4$ & $\% 79,6$ & $\% 100,0$ \\
\hline İş Hayatı İle İlişkiler & 40 & 63 & 103 & $\% 38,8$ & $\% 61,2$ & $\% 100,0$ \\
\hline Araştırma /Yayın Paylaşımı & 21 & 92 & 103 & $\% 20,4$ & $\% 79,6$ & $\% 100,0$ \\
\hline Öğrenci Kulüpleri & 3 & 100 & 103 & $\% 2,9$ & $\% 97,1$ & $\% 100,0$ \\
\hline Çeşitli Projeler & 13 & 90 & 103 & $\% 12,6$ & $\% 87,4$ & $\% 100,0$ \\
\hline Staj Uygulamaları & 29 & 84 & 103 & $\% 28,2$ & $\% 74,8$ & $\% 100,0$ \\
\hline
\end{tabular}

Tablo 13. Vakıf Üniversitelerinin Danışmanlık Hizmetlerine Yönelik Bulgular

\begin{tabular}{|c|c|c|c|c|c|c|}
\hline \multirow{3}{*}{$\begin{array}{l}\text { ÜNIVERSITELER VE } \\
\text { DANIŞMANLIK } \\
\text { HİZMETLERİ }\end{array}$} & \multicolumn{6}{|c|}{ VAKIF ÜNIVERSITELERİ } \\
\hline & \multicolumn{2}{|c|}{ FREKANS } & \multirow{2}{*}{ TOPLAM } & \multicolumn{2}{|c|}{ YÜZDE } & \multirow{2}{*}{ TOPLAM } \\
\hline & VAR & YOK & & VAR & YOK & \\
\hline Lisansüstü Program & 7 & 61 & 68 & $\% 10,3$ & $\% 89,7$ & $\% 100,0$ \\
\hline Ölçme ve Değerlendirme & 7 & 61 & 68 & $\% 10,3$ & $\% 89,7$ & $\% 100,0$ \\
\hline Eğitim Programları & 35 & 33 & 68 & $\% 51,5$ & $\% 48,5$ & $\% 100,0$ \\
\hline Kariyer Bilgi Sistemi & 15 & 53 & 68 & $\% 22,1$ & $\% 77,9$ & $\% 100,0$ \\
\hline İş Hayatı İle İlişkiler & 33 & 35 & 68 & $\% 48,5$ & $\% 51,5$ & $\% 100,0$ \\
\hline Araştırma /Yayın Paylaşımı & 12 & 56 & 68 & $\% 17,6$ & $\% 82,4$ & $\% 100,0$ \\
\hline Öğrenci Kulüpleri & 2 & 66 & 68 & $\% 2,9$ & $\% 97,1$ & $\% 100,0$ \\
\hline Çeşitli Projeler & 3 & 65 & 68 & $\% 4,4$ & $\% 95,6$ & $\% 100,0$ \\
\hline Staj Uygulamaları & 25 & 43 & 68 & $\% 36,8$ & $\% 63,2$ & $\% 100,0$ \\
\hline
\end{tabular}

Kamu ve Vakıf Üniversitelerinin kariyer merkezlerinde yürüttükleri danışmanlık faaliyetlerinin içeriği incelendiğinde; kamu üniversitelerinin \% 38,8 oranında; vakıf üniversitelerinin ise \% 51,5 oranında eğitim programlarına yer verdikleri görülmüştür. İş hayatı ile ilişkiler geliştiren, iş yaşamından konuklara kariyer etkinliklerinde yer veren, özel sektör ziyaretleri vb etkinlikleri gerçekleştiren kamu üniversitesi oranı \% 38,8 iken, vakıf üniversitesi oranı \% 48,5 şeklinde ortaya çıkmıştır. Kamu üniversitelerinin \% 28,2'si, vakıf üniversitelerinin ise \% 36,8'i kariyer merkezlerine "staj"a yönelik bilgilendirme, destek faaliyetlerinde bulunmaktadır. Kariyer merkezine sahip olan kamu üniversitelerinin \% 20,4'ü; vakıf üniversitelerinin ise \% 22,1'inin web sayfalarında "kariyer bilgi sistemi"ni kullandığı görülmüştür. Kariyer merkezler web sayfalarından Araştırma veya yayın paylaşan kamu üniversiteleri oranının \% 20,4; vakıf üniversiteleri oranının ise \% 17,6 olduğu tespit edilmiştir. Kariyer merkezlerine lisansüstü programlara yönelik bilgilendirme yapan, ayrıca bu konuda özel hizmet veren kamu üniversitesi oranı \% 9,7 iken, vakıf üniversitesi oranı \% 10,3 şeklinde ortaya çıkmıştır. Ölçme ve değerlendirme faaliyetlerine yer verme de hem kamu hem de vakıf üniversitelerinde söz konusudur. Kamu üniversitelerinde bu oran \% 8,7 iken, vakıf üniversitelerinde \% 10,3'tür. Öğrenci kulüplerine yönelik yönlendirme yapan kamu üniversitesi ve vakıf üniversitesi oranı 
$\%$ 2,9`dur. Öğrencileri çeşitli projeler konusunda yönlendiren kamu üniversitesi oranı $\%$ 12,6 iken; vakıf üniversitesi oranı \% 4,4 şeklinde ortaya çıkmıştır. Bu projelerin özellikle TÜBİTAK projeleri, Uluslar arası projeler alanında olduğu görülmüştür.

Önemli dikkate çeken noktalardan biri de bu merkezlerin danışmanlık hizmetlerini verirken belirli saat ve tarih aralıklarından farklı akademisyenler tarafından bu hizmetleri yürüttükleridir. Ayrıca kamu üniversitelerinde az sayıda da olsa "mülakat provaları" yapıldığı bu provaların vakıf üniversiteleri kariyer merkezlerinde daha fazla yapıldığı görülmüştür. Bu provalara katılmak isteyen öğrencilerin randevu sistemi ile başvuruda bulunmaları merkezlerin yönlendirmelerinden biridir. Vakıf üniversitelerinde özellikle atölye çalışmalarının yaygın şekilde kullanıldığ tespit edilmiştir. Kariyer kampı oluşturan ve kariyer elçileri adı altında takım kuran vakıf üniversitesi örneği de mevcuttur.

\section{SONUÇ}

Çalışmada elde edilen en önemli bulgu; üniversitelerin çoğunun yeni kurulmasına rağmen neredeyse yarısının kariyer merkezine sahip olduğu yönünde ortaya çıkmıştır. Ancak bu oran vakıf üniversitelerinde biraz daha yüksek çıkmıştır. Buradan hareketle ve incelenen üniversiteler dikkate alındığında vakıf üniversitelerinin bu alanda daha aktif olduğu söylenebilir. Vakıf üniversitelerinin kariyer merkezi web sayfalarının büyük bölümünde daha aktif bulgulara rastlanmıştır. Merkezlerin sayfalarından verilen hizmetlerden her iki kurum türü için de "haberler ve duyurular, ilgili form veya belgeler, sosyal ağ sayfaları" oranları yüksek çıkmıştır. Ancak bu oranlar vakıf üniversiteleri açısından özellikle "form ve belgeler ile sosyal ağ" alanında daha yüksek çıkmıştır. Bu bakımdan vakıf üniversitelerinin kariyer merkezi web sayfalarını kamu üniversitelerine göre daha aktif şekilde kullandıkları söylenebilir. Çünkü "randevu sistemi, mülakat provaları, atölye çalışmaları vb" gibi pek çok farklı uygulamaya vakıf üniversitelerinin web sayfasında rastlanmıştır. Ayrıca vakıf üniversitelerinin kariyer merkezlerinin faaliyetlerinin de kamu üniversitelerine göre araştırma ve uygulama merkezi konseptinden farklılaştığı görülmüştür. Vakıf üniversitelerinin özellikle kariyer yaşam programı adı altında uyguladıkları programlar bu farklılaşmayı ön plana çıkarmıştır. Kariyer planlama alanında ise hem kamu hem de vakıf üniversitelerinin "kendini tanıma, iş dünyasını tanıma, iş bulma" faaliyetlerini yoğun olarak yürüttükleri tespit edilmiştir. Daha çok kariyer etkinliklerinde eğitimlerin verilmesi, iş dünyasını tanıtmak adına konferansların düzenlenmesi, staj uygulamaları hakkında ayrıntılı bilgi paylaşımları bu bulguları destekler niteliktedir.

Tüm bu veriler dikkate alındığında Türkiye' de hem kamu üniversitelerinde hem de vakıf üniversitelerinde kariyer planlama ve kariyer geliştirme alanında faaliyetlerin başladığı söylenebilir. Bu durum 2013 yılından Yükseköğretim Kurulu toplantısında da dile getirilmiştir. Ancak kamu üniversitelerine göre vakıf üniversitelerinin araştırmada incelenen üniversiteler dikkate alındığında, kariyer merkezleri alanında daha aktif oldukları söylenebilir. Rastlanan bulgular arasında özellikle kamu üniversitelerinde Resmi Gazete' de yayınlanan yönetmelik ile kariyer 
merkezlerinin çok yakın bir tarihte kuruldukları gözlenmiştir. Bu durum Avrupa Üniversiteleri ile kıyaslandığında geç kalınmış bir süreç olarak düşünülebilir. Bugün pek çok üniversitede farklı araştırma ve uygulama merkezleri sayıca fazla şekilde kurulmuş, akıbeti ve faaliyetleri konusunda aktifliği tartışılır hale gelmiştir. Bu çalışmada üniversiteler araştırılırken hemen hemen üniversitelerin tamamında "Kadın Araştırmaları Merkezi"ne de rastlanmıştır. Hedef kitlesinin öğrenciler olduğu düşünülen üniversitelerde bu merkezlerin açılıp, kariyer merkezlerinin olmaması eleştirilecek bir durumdur. Hem sürecin Türkiye' de yeni başlaması hem de farklı merkezlerin üniversiteler örgüt yapısında mevcut iken kariyer merkezlerinin olmaması adına bu durumun gündeme alınması söz konusu olabilir. Her üniversitede öğrenciye vizyon kazandıracak kariyer merkezlerinin açılması, bu merkezlerin "üniversite yönetimi, akademisyenler, öğrenciler, iş dünyası" paydaşları ile desteklenmesi, hepsinden önemlisi açılan merkezlerin sadece yönetmelik üzerinden değil aktif şekilde faaliyetlerini yürütmesi sağlanabilir.

\section{KAYNAKÇA}

Adıgüzel, O. (2012). Türkiye'de Gençlerin Kariyer Planlamasını Etkileyen Faktörler Ve Üniversite Hazırlık Öğrencileri Üzerine Bir Araştırma (Yayımlanmamış Doktora Tezi), Kütahya: Dumlupınar Üniversitesi Sosyal Bilimler Enstitüsü

Anafarta, N. (2002). Bireysel Kariyer Danışmanı Olarak Rehber (Mentor). Canakkale Üniversitesi İktisadi ve İdari Bilimler Dergisi. 3(2): 115-128.

Anafarta, N. (2001). Orta Düzey Yöneticilerin Kariyer Planlamasına Bireysel Perspektif, Akdeniz İktisadi ve İdari Bilimler Fakültesi Dergisi, 3(2): 1-17.

Barutçugil, İ. (2004). Stratejik İnsan Kaynakları Yönetimi, İstanbul: Kariyer Yayıncılık.

Can, H. ve Güney, S. (2007). Genel İşletme İlkeler Kavramlar ve Kurumlar. Ankara: Arıkan Basım Yayın Dağıtım

Cevher, E. (2013). Vakıf Üniversitelerinde Uygulanabilecek Rekabet Stratejileri Üzerine Bir Araştırma (Basılmamış Doktora Tezi), Isparta. Süleyman Demirel Üniversitesi Sosyal Bilimler Enstitüsü

Çetinsaya, G. (2014). Büyüme, Kalite, Uluslararasılaşma: Türkiye Yükseköğretimi İçin Bir Yol Haritası, Yükseköğretim Kurulu Yayın No. 2014/ 2

Demirbilek, T. (1994). Örgütlerde Kariyer Danışmanlığı Hizmetleri. Dokuz Eylül Üniversitesi İktisadi ve İdari Bilimler Fakültesi Dergisi. 9(2): 71-85

Fischer, B.B., Klaghofer, R., Abel, T., Buddeberg, C. (2003). The Influence Of Gender And Personality Traits On The Career Planning Of Swiss Medical Students Swiss. Med Wkly 133

Güney, S. (2000).Yönetim ve Organizasyon El Kitabı, Ankara: Nobel Yayın Dağıtım.

Gürüz, D. ve G. Ö. Yaylacı. (2009). İletişimci Gözüyle İnsan Kaynakları Yönetimi. İstanbul: MediaCat.

Gürüz, D. ve G. Ö. Yaylacı. (2009). İletişimci Gözüyle İnsan Kaynakları Yönetimi. İstanbul: MediaCat.

İbicioğlu, H. (2011). İnsan Kaynakları Yönetimi. Ankara: Alter Yayıncılık. 
Külekçi, E. (2013).“4+4+4 Eğitim Sistemi Kapsamında Birleştirilmiş Sınıf Uygulamasına İlişkin Öğretmen Görüşlerinin Değerlendirilmesi. Eğitim ve Öğretim Araştırmaları Dergisi Journal of Research in Education and Teaching, (2)2: 369-371.

Noe, R. (2009). İnsan Kaynaklarının Eğitimi ve Geliştirilmesi. (Çev: Canan ÇETíN). İstanbul:Beta Yayınları.

Rood, A. (1965). Realizing Your Executive Potential. Mc Graw Hill Inc.

Sağdıç, M. ve Demirkaya, M. (2009). Üniversite Öğrencilerinin Kariyer Gelişim Planlarına İlişkin Yaklaşımları, Sosyal Bilimler Enstitüsü Dergisi, 2(6): 233-246.

Sav, D. (2008). Bireysel Kariyer Planlamada Etkili Olan Faktörler Ve Üniversitelerin Etkisi Üzerine Bir Araştırma, (Basılmamış Yüksek Lisans Tezi). Isparta: Süleyman Demirel Üniversitesi Sosyal Bilimler Enstitüsü

Ünver, Y. (2005). Ankara Üniversitesi Sosyal Bilimler Enstitüsü, İnsan Kaynakları Yönetimi ve Kariyer Danışmanlığı Anabilim dalı, İşletmelerde Kariyer Yönetimi ve Performans Değerlendirme Sistemleri, Dönem Projesi

Tavşancıl, E., Aslan, E., (2001). İçerik Analizi Ve Uygulama Örnekleri, İstanbul: Epsilon Yayınları.

Yalım, D. (2005). İnsan Kaynaklarında Yeni Eğilimler. İstanbul: Hayat Yayınları.

Yılmaz, İ.A., Dursun B., Pektaş K. ve Altay A. (2012). Üniversite Öğrencilerinin Kariyer Seçimlerinin Demografik Özellikler Açısından İncelenmesi: Pınar Hisar MYO Örneği, Electronic Journal Of Vocational Collages Aralık, 9-21.

Yıldırım, A. ve Şimşek, H. (2004). Sosyal Bilimlerde Nitel Araştırma Yöntemleri, Seçkin Yayıncılık, 4. Basım, Ankara.

Yılmaz, S. (2011). İlköğretim Dördüncü Sınıf Öğrencilerinin Birlikte Çalışma”Ya İlişkin Algıları, Ahi Evran Üniversitesi Ĕ̆itim Fakültesi Dergisi., 12( 1): 1-14

(http://www.yok.gov.tr/web/ogrenci/kariyer-merkezleri-toplantisi, Erişim: 16.06.2015)

(www.yok.gov.tr. Erişim: 16.06.2015) 